\title{
Pertukaran Sosial dalam Online Dating (Studi Pada Pengguna Tinder di Indonesia)
}

\author{
Lukman Saleh Waluyo, Ilya Revianti \\ 1. Departemen Ilmu Komunikasi, Fakultas Ilmu Sosial dan Ilmu Politik, Universitas Indonesia, Gedung \\ Komunikasi Lt. 2 FISIP UI, Kampus UI Jawa Barat, 16424, Indonesia \\ 2. Departemen Ilmu Komunikasi, Fakultas Ilmu Sosial dan Ilmu Politik, Universitas Indonesia, Gedung \\ Komunikasi Lt. 2 FISIP UI, Kampus UI Jawa Barat, 16424, Indonesia \\ E-mail: lukman.saleh@ui.ac.id
}

\begin{abstract}
Abstrak. Penelitian ini dilatarbelakangi oleh perkembangan digital yang pesat di Indonesia beberapa tahun belakangan yang mengubah cara orang mencari jodoh sehingga banyak bermunculan aplikasi dan biro jodoh online. Banyak pengguna online dating yang tidak mendapatkan pasangan sehingga membuat perkembangan pengguna aplikasi online dating atau biro jodoh online menjadi stagnan. Adapun aplikasi kencan online dalam penelitian ini adalah Tinder karena salah satu aplikasi kencan online yang paling banyak digunakan. Tesis ini membahas bagaimana perilaku pengambilan keputusan pengguna Tinder untuk melanjutkan hubungan lebih jauh dengan calon pasangan yang ditemuinya dalam Tinder berdasarkan Teori Pertukaran Sosial dan hal-hal apa saja yang turut mempengaruhi proses pengambilan keputusan tersebut. Penelitian ini menggunakan Teori Pertukaran Sosial dengan konsep keuntungan dan pengorbanan. Penelitian ini menggunakan paradigma pascapositivisme. Peneliti akan menggunakan metode kualitatif deskriptif dengan tujuan menggambarkan peranan pertukaran sosial dalam online dating secara detail dan memperinci informasi yang ada. Temuan yang didapat dari penelitian ini adalah pengguna online dating mencari keuntungan dari calon pasangannya dalam berbagai tahap, yaitu tahap pertama, tahap pengecekan latar belakang, dan tahap utama.Untuk komponen pengorbanan terdapat pengorbanan yang bernilai sama diantara pria dan wanita dan juga ada yang bernilai berbeda.
\end{abstract}

Keywords: Digital; Online Dating; Relationship; Social Exchange; Tinder.

\section{Pendahuluan}

Dalam lima tahun terakhir, pertumbuhan internet cukup pesat dengan jumlah pengguna Internet yang terus bertambah. Saat ini jumlah pengguna Internet di tanah air mencapai 72 juta pengguna Internet. Hal tersebut mengubah banyak hal. Cara mengkonsumsi media, cara berpergian, dan juga cara mencari jodoh. Banyak orang yang mencari pasangan melalui aplikasi kencan online Tinder ternyata membuahkan hasil. Ada beberapa orang yang menemukan kekasih hingga menemukan jodoh lewat Tinder. Tapi tidak semuanya berakhir dengan keberhasilan. Mengapa ada yang bisa sukses, sedangkan ada juga yang tidak sukses? Jika kita telaah dari kacamata teoritis, manusia memandang suatu hubungan dalam konteks transaksional. Sebagai sebuah teori, Teori Pertukaran Sosial menyatakan bahwa pendekatan pada pertukaran hubungan sosial ini seperti teori ekonomi yang didasarkan pada perbandingan pengorbanan dan keuntungan (Cost and Rewards). 
Tujuan penelitian ini adalah untuk mengetahui:

1. Hal yang dianggap sebagai keuntungan yang didapatkan dari pasangan dalam online dating yang mempengaruhi keputusan untuk melanjutkan hubungan

2. Hal yang dianggap sebagai pengorbanan yang diberikan kepada pasangan dalam online dating sehingga memutuskan untuk memberhentikan hubungan lebih jauh lagi

3. Bagaimana agar mempunyai tingkat perbandingan (CL) yang lebih besar dibandingkan dengan pasangan sebelumnya

4. Bagaimana agar mempunyai tingkat perbandingan alternatif (CLalt) dibandingkan alternatif calon pasangan online dating lainnya

\section{Tinjauan Teoritis}

Teori Pertukaran Sosial dikembangkan oleh psikolog John Thibaut dan Harold Kelley (1959), sosiolog George Homans (1961), Richard Emerson (1962), dan Peter Blau (1964). Teori Pertukaran Sosial (Social Exchange Theory - SET) adalah pendekatan yang luas yang digunakan untuk menjelaskan dan memprediksi pemeliharaan hubungan. Sebagai sebuah teori, SET menyatakan bahwa pendekatan pada pertukaran hubungan sosial ini seperti teori ekonomi yang didasarkan pada perbandingan pengorbanan dan keuntungan (Cost and Rewards). Oleh karena itu, teori ini melihat hubungan pribadi dalam pandangan pengorbanan berbanding keuntungan. Keuntungan apa yang Anda terima dari hubungan yang berjalan. Dan berapa besar pengorbanan yang harus dikeluarkan untuk mendapatkan keuntungan tersebut.

Para peneliti Teori Pertukaran Sosial berpendapat bahwa semua orang menilai hubungan mereka dengan melihat pengorbanan dan keuntungan. Sudut pandang pertukaran sosial berpendapat bahwa orang menghitung nilai keseluruhan dari sebuah hubungan dengan cara keuntungan yang diterima dikurangi oleh pengorbanan yang sudah diberikan (Monge dan Contractor,2003).

$\underline{\text { Nilai = keuntungan }- \text { pengorbanan }}$ 
Hubungan yang positif adalah hubungan di mana nilai menghasilkan angka positif karena keuntungan yang diterima lebih besar daripada pengorbanan yang sudah diberikan. Sedangkan hubungan dengan nilai negatif terjadi jika pengorbanan melebihi keuntungan yang diterima. Sehingga hubungan ini cenderung berdampak negatif untuk partisipannya. Teori Pertukaran Sosial bahkan melangkah lebih jauh dengan memprediksikan bahwa hasil nilai dari sebuah hubungan mempengaruhi hasil akhir (outcome) apakah orang akan meneruskan suatu hubungan atau mengakhirinya. Hubungan yang positif biasanya dapat bertahan, sedangkan hubungan yang negatif mungkin akan berakhir.

Setiap individu secara sukarela ikut dan menetap di dalam suatu hubungan hanya selama hubungan itu dianggap memuaskan dalam hal keuntungan dan pengorbanannya (Thibault \& Kelley, 1959). Pertukaran sosial memandang hubungan melalui metafora pasar dimana tiap orang bertindak berdasarkan tujuan pribadi untuk mencari keuntungan. (Sabatelli \& Shehan, 1993)

Teori Pertukaran Sosial adalah perspektif psikologi sosial dan sosiologi yang menjelaskan perubahan sosial dan stabilitas sebagai proses pertukaran yang dinegosiasikan antara pihakpihak. Teori Pertukaran Sosial berpendapat bahwa hubungan manusia dibentuk oleh penggunaan analisis subjektif keuntungan-pengorbanan dan perbandingan dari berbagai alternatif.

Kepentingan diri sendiri dan saling keterbergantungan adalah hal inti dari pertukaran sosial. Ini adalah bentuk dasar dari interaksi ketika dua atau lebih pelaku memiliki sesuatu yang bernilai bagi satu sama lain. Dalam pertukaran sosial, kepentingan diribukan hal yang negatif.

Malahan, ketika kepentingan diri sudah dikenali itu akan bertindak sebagai pembimbing hubungan interpersonal untuk kemajuan kedua belah pihak (Roloff,1981)

Thibaut dan Kelley melihat interdependensi atau saling keterbergantungan orang sebagai masalah utama untuk studi perilaku sosial. Menurut definisi saling ketergantungan mereka, hasil (outcome) didasarkan pada kombinasi upaya kedua pihak dan saling mengatur serta saling melengkapi. 
Teori Pertukaran Sosial melihat pertukaran sebagai perilaku sosial yang dapat mengakibatkan baik hasil ekonomi maupun sosial. Teori Pertukaran Sosial telah dianalisis secara umum dengan memperbandingkan antara interaksi manusia dengan perdagangan. Tidak seperti pertukaran ekonomi, unsur pertukaran sosial cukup bervariasi dan tidak dapat direduksi menjadi nilai tukar kuantitatif tunggal. Menurut Stafford, pertukaran sosial melibatkan hubungan dengan orang lain.; melibatkan kepercayaan lebih fleksibel; dan jarang melibatkan proses tawar-menawar eksplisit.

Dalam Teori Pertukaran Sosial, dikatakan juga bahwa kita akhirnya akan kehilangan hubungan yang kita miliki karena kita merasa hubungan tersebut sudah tidak lagi memberi manfaat bagi kita dengan cara apapun. Kita merasa seperti sudah tidak ada gunanya lagi menjalin komunikasi karena sudah tidak ada keuntungan atau imbalan lagi. Setelah ini terjadi, kita mencari partner dan sumber daya baru. Kita melalui proses ini sehari-hari.

Sebuah studi berjudul, "Faktor-faktor yang menyebabkan inisiasi Kontak interpersonal dalam Situs Kencan: Pandangan dari Teori Pertukaran Sosial yang diterapkan pada media baru (situs kencan online)." Studi ini menemukan faktor-faktor yang berbeda yang terlibat ketika seorang individu memutuskan untuk menjalin hubungan online. Secara keseluruhan penelitian ini mengikuti ide Teori Pertukaran Sosial, "orang tertarik kepada mereka yang memberi mereka manfaat". (Shtatfeld; Barak. 2009).

Contoh lain adalah studi Berg tentang perkembangan persahabatan antara teman sekamar. Penelitian ini menemukan bagaimana proses pertukaran sosial berubah siring waktu berjalan dengan mengukur pengungkapan diri / self-disclosure. Menurut penelitian, jumlah manfaat yang diberikan seseorang dan Comparison of Alternatives menjadi faktor paling penting dalam menentukan liking dan satisfaction.

Jadi secara ringkas Teori Pertukaran Sosial (Social Exchange Theory - SET) adalah pendekatan yang luas yang digunakan untuk menjelaskan dan memprediksi pemeliharaan hubungan. SET menjelaskan kapan dan mengapa individu melanjutkan dan mengembangkan beberapa hubungan pribadi, yang dilain waktu juga mengakhiri hubungan yang lain. Selain itu, SET juga memperhitungkan akan seberapa puas Anda dengan hubungan yang Anda pilih untuk dipertahankan. 


\section{Metode Penelitian}

Pascapositivisme adalah aliran yang ingin memperbaiki kelemahan pada positivisme. Satu sisi pascapositivisme sependapat dengan positivisme bahwa realitas itu memang nyata ada sesuai hukum alam. Tetapi pada sisi lain post-positivisme berpendapat manusia tidak mungkin mendapatkan kebenaran dari realitas apabila peneliti membuat jarak dengan realitas atau tidak terlibat secara langsung dengan realitas. Hubungan antara peneliti dengan realitas harus bersifat interaktif, untuk itu perlu menggunakan prinsip triangulasi melalui penggunaan bermacam-macam metode, sumber data, data, dan lain-lain. Dengan demikian, peneliti akan menggunakan paradigma pascapositivisme dalam melakukan penelitian ini. Sesuai dengan tujuannya, penelitian ini akan menggunakan pendekatan kualitatif karena memungkinkan peneliti untuk mempelajari isu-isu tertentu secara mendalam dan mendetail karena pengumpulan datanya tidak dibatasi pada kategori-kategori tertentu saja.

Jenis penelitian yang dilakukan adalah penelitian deskriptif kualitatif. Penelitian yang bersifat deskriptif adalah suatu penelitian yang berusaha untuk memberikan gambaran suatu kondisi, sifat, karakteristik, dari suatu fenomena atau obyek penelitian, atau hanya menggambarkan apa adanya tentang suatu variabel, gejala atau suatu keadaan. Penggunaan tipe ini dilakukan dengan alasan karena peneliti berusaha menggambarkan, menuturkan, dan menafsirkan data yang ada, misalnya tentang situasi yang dialami, suatu hubungan, kegiatan, pandangan, sikap yang menampak, atau suatu proses yang berlangsung, pengaruh yang sedang bekerja, kelainan yang sedang muncul, kecenderungan yang menampak dan sebagainya.

\section{Hasil Penelitian}

Subjek penelitian adalah orang-orang yang menggunakan aplikasi Tinder dari berbagai latar belakang Subjek berjumlah enam orang terdiri dari tiga pria dan tiga wanita agar memperoleh informasi dari dua sudut pandang pria dan wanita serta berjumlah ganjil (tiga pria dan tiga wanita) agar dapat dengan mudah mendapatkan kecenderungan pendapat yang dominan. Informan penelitian diwawancara mengenai pendapat mereka tentang bagaimana mereka memutuskan untuk melanjutkan hubungan yang lebih dalam di dalam aplikasi Tinder berdasarkan empat komponen Teori Pertukaran Sosial yaitu keuntungan (benefit), pengorbanan (cost), tingkat perbandingan (comparison level), dan tingkat perbandingan alternatif (comparison level of alternatives). 
Faktor keuntungan adalah faktor-faktor yang dianggap oleh informan memberikan keuntungan dari calon pasangan yang ditemui dalam Tinder kepada mereka. Yang dimana dari pertimbangan terhadap faktor inilah mereka menentukan keputusan untuk melanjutkan hubungan lebih jauh terhadap calon pasangan atau tidak.

Faktor pengorbanan adalah faktor-faktor yang dianggap oleh informan mengeluarkan pengorbanan dari informan kepada calon pasangan yang ditemui dalam Tinder. Yang dimana dari pertimbangan terhadap faktor ini jugalah mereka menentukan keputusan untuk melanjutkan hubungan lebih jauh terhadap calon pasangan atau tidak. Teori Pertukaran Sosial menyatakan bahwa hasil akhir sebuah hubungan adalah dari nilai keuntungan yang didapat dikurangi nilai pengorbanan yang dikeluarkan.

Comparison level. Disini para informan diminta untuk membandingkan nilai antara pasangannya sekarang dengan pasangan sebelumnya, baik itu didapat dari Tinder ataupun tidak. Nilai disini adalah keuntungan yang didapat dikurangi pengorbanan yang diberikan.

Jawaban yang diberikan informan menyatakan bahwa ada yang menilai pasangan yang sekarang nilainya lebih baik dibandingkan yang dulu, ada juga yang mengatakan bahwa pasangan yang sebelumnya lebih baik nilainya dibanding yang sekarang. Tetapi sesuai Teori Pertukaran Sosial tentang comparison level, mereka menyatakan jika yang nilainya lebih baik pasangan yang sekarang maka dia merasa puas dengan hubungannya yang sekarang, dan jika pasangan yang sebelumnya lebih baik nilainya maka mereka merasakan ketidak puasannya dengan hubungan yang sekarang.

Comparison level of alternatives. Disini para informan diminta untuk membandingkan nilai antara pasangannya sekarang dengan alternatif pasangan lainnya, baik itu yang didapat dari Tinder ataupun tidak. Nilai disini adalah keuntungan yang didapat dikurangi pengorbanan yang diberikan.

Jawaban yang diberikan informan menyatakan bahwa ada yang menilai pasangan yang sekarang nilainya lebih baik dibandingkan yang dulu, ada juga yang mengatakan bahwa pasangan yang sebelumnya lebih baik nilainya dibanding yang sekarang. Tetapi sesuai Teori Pertukaran Sosial tentang comparison level of alternatives, mereka menyatakan jika yang nilainya lebih baik pasangan yang sekarang maka mereka akan tetap pada hubungannya yang sekarang, dan jika alternatif pasangan yang lain lebih baik nilainya maka mereka akan mengakhiri hubungan yang sekarang. 


\section{Pembahasan}

Adalah penting bagi para pengguna online dating untuk mengetahui karakteristik perbedaan yang dimiliki dalam online dating dibandingkan offline. Analisa mengenai hubungan sosial yang terjadi menurut keuntungan dan pengorbanan ini merupakan salah satu ciri khas teori pertukaran. Teori pertukaran ini memusatkan perhatiannya pada tingkat analisis mikro, khususnya pada tingkat kenyataan sosial antarpribadi (interpersonal). Homans dalam analisisnya berpegang pada keharusan menggunakan prinsip-prinsip psikologi individu untuk menjelaskan perilaku sosial daripada hanya sekadar menggambarkannya. Akan tetapi Blau di lain pihak berusaha beranjak dari tingkat pertukaran antarpribadi di tingkat mikro, ke tingkat yang lebih makro yaitu struktur sosial. Ia berusaha untuk menunjukkan bagaimana struktur sosial yang lebih besar itu muncul dari proses-proses pertukaran dasar. (Homans, 1950). Dalam online dating, tingkat mikro tersebutlah yang memiliki perbedaan dengan offline dating, salah satu penyebabnya karena keterbatasan yang dimiliki oleh online dating.

Adalah menarik bagi peneliti maupun peneliti berikutnya untuk memperdalam topik seputar Teori Pertukaran Sosial yang diterapkan dalam online dating yang terbentuk di era Internet ini. Beberapa pertanyaan yang dapat diajukan antara lain:

1. Apa saja yang menjadi ciri unik Teori Pertukaran Sosial dalam online dating?

\section{Bagaimana penerapan Teori Pertukaran Sosial yang baik dalam online dating?}

3. Seberapa sesuaikah asumsi-asumsi Teori Pertukaran Sosial dengan pengalaman pengguna aplilasi Tinder dan prospek masa depan mereka? Apakah memang orang biasanya bertindak hanya didasarkan pada kepentingan pribadi? Kapan mereka mungkin tidak berlaku demikian?

4. Adakah yang membuat teori ini lebih mungkin diuji dalam penerapannya di online dating? Apakah mungkin untuk mengukur keuntungan dan pengorbanan dalam cara yang tepat dan dapat diamati?

5. Apakah penerapa teori ini dapat membantu pengguna dalam menggunakan online dating?

6. Bagaimana Teori Pertukaran Sosial menjelaskan hal-hal tidak egois yang dilakukan pengguna online dating yang tampaknya tidak dihitung untuk mendapatkan keuntungan bagi mereka? 
7. Apakah pengguna online dating pernah bertahan dalam sebuah hubungan karena merasa tidak memiliki alternatif lain? Bagaimana Teori Pertukaran Sosial membantu menjelaskan perilaku ini?

\section{Kesimpulan}

Ada beberapa faktor yang dianggap sebagai keuntungan dari pasangan dalam Tinder yang mempengaruhi keputusan untuk melanjutkan hubungan berdasarkan data yang sudah didapatkan.

Untuk faktor pertama, walaupun bukan yang paling utama, adalah faktor ketampanan atau kecantikan, dimana para pengguna Tinder baik pria dan wanita setuju bahwa faktor ini adalah proses filtering pertama kali untuk kemudian masuk ke tahap selanjutnya yaitu pengecekan latar belakang calon pasangannya. Untuk tahap ini ada kecenderungan bahwa pria lebih mempertimbangkan hal ini dibandingkan para wanita, dan bagi para pria, faktor kecantikan itu satu paket dengan keseksian atau kemolekan tubuh dimana para wanita tidak menganggapnya seperti itu.

Lalu setelah melewati proses filtering mereka akan masuk kepada tahap pengecekan latar belakang dimana masing-masing orang mempunyai standar yang berbeda-beda. Faktor-faktor yang masuk ke dalam tahapan ini diantaranya adalah kejelasan identitas, karena online dating dianggap hal yang masih rawan, dan wanita cenderung lebih mempertimbangkan hal ini dibanding pria. Faktor pendidikan dimana faktor ini mempunyai standar minimal untuk faktor ini dimana standarnya berbeda-beda setiap orang. Dan bagi informan wanita cenderung lebih mempertimbangkan hal ini dibanding informan pria. Faktor pekerjaan, dimana lagi-lagi para wanita cenderung lebih mempertimbangkan hal ini dibanding pria, dimana para wanita menginginkan calon pasangan yang paling tidak mempunyai pekerjaan yang setingkat dengan mereka. Lalu ada faktor usia dimana para wanita menginginkan pasangan yang berusia minimal sama sampai 5 tahun diatasnya, dan pria menginginkan calon pasangan yang rentang usianya tidak terlalu jauh dengan mereka. Dan ada faktor kekayaan dimana pria dan wanita menginginkan pasangan yang tingkat kekayaannya tidak terpaut jauh dengan mereka dan juga tidak ingin apabila pasangannya tidak mempunyai tingkat kekayaan yang layak. Kemudian ada faktor agama dimana jika dalam hubungan yang serius, baik pria maupun wanita menginginkan pasangan yang minimal agamanya sama dengan mereka, sedangkan tingkat 
ketaatan dalam menjalankan agama tersebut tidak terlalu berpengaruh. Faktor ras dimana pria lebih menyukai wanita yang berkulit putih dan wanita mempunyai ras-ras tertentu yang mereka tidak sukai tergantung dari preferensi masing-masing wanita. Faktor status hubungan dimana wanita tidak menginginkan pria yang sudah mempunyai pasangan atau duda, dan bagi pria mempunyai kecenderungan untuk tidak terlalu menginginkan wanita yang sudah menjadi janda jika tujuannya adalah untuk suatu hubungan yang serius. Kemudian ada faktor keseriusan dalam berkomitmen dimana wanita menganggap faktor ini sebagai sebuah keuntungan jika memang mereka berniat mencari hubungan yang serius, dan bagi pria menganggap baik calon pasangan mempunyai keinginan berkomitmen atau tidak tetap sebagai sebuah keuntungan yang mereka pertimbangkan untuk memperdalam hubungan. Karena mereka memandang selama mereka menyukai calon pasangan tersebut, keduanya memiliki keuntungan bagi mereka. Apabila tidak ingin serius jadi hubungan yang main-main saja, jika calon pasangan ingin serius ya bisa dilanjutkan sebagai hubungan yang berkomitmen.

Tahap selanjutnya apabila telah lolos tahap pengecekan latar belakang, adalah tahap yang paling utama yang menentukan apakah hubungan akan berlanjut ke hubungan yang lebih dalam atau tidak. Dalam tahap ini terdapat beberapa faktor, diantaranya adalah: kenyambungan, keasyikan dan kenyamanan dalam mengobrol; kecerdasan; dan sifat humoris. Untuk faktor kenyambungan, keasyikan, dan kenyamanan saat mengobrol, para informan setuju bahwa faktor ini adalah salah satu faktor paling penting yang mereka pertimbangkan, karena untuk melanjutkan hubungan ke jenjang yang lebih dalam mereka akan ketemuan setelah mengobrol di dalam Tinder. Yang dimaksud kenyamanan disini adalah saat mengobrol mereka menemukan kecocokan, obrolannya nyambung, becandanya nyambung, dan mereka bisa jadi diri mereka sendiri. Karena menurut mereka dari nyambung, nyaman, kemudian bisa menjadi rasa sayang.

Ada beberapa faktor yang dianggap sebagai pengorbanan kepada pasangan dalam Tinder yang mempengaruhi keputusan untuk melanjutkan hubungan berdasarkan data yang sudah didapatkan. Faktor-faktor tersebut ada yang sama-sama dianggap sebagai sebuah pengorbanan yang nilainya sama antara pria dan wanita, dan ada juga faktor-faktor pengorbanan tetapi besaran nilainya dianggap berbeda oleh pria dan oleh wanita. Faktor-faktor pengorbanan yang sama nilainya diantara pria dan wanita diantaranya adalah faktor resiko diteror dan faktor kecanggungan. 
Faktor resiko diteror adalah mereka menganggap calon pasangannya punya potensi untuk meneror maka mereka enggan untuk melanjutkan hubungan lebih jauh. Sedangkan faktor kecanggungan adalah pertimbangan saat akan bertemu dan melanjutkan hubungan lebih jauh dengan calon pasangan, dan apabila merasa akan canggung membuat para informan jadi tidak ingin melanjutkan hubungan lebih jauh dengan calon pasangan.

Sedangkan faktor yang dianggap pengorbanan tapi besaran nilainya dianggap berbeda oleh pria dan oleh wanita adalah faktor biaya finansial, faktor investasi emosi, dan faktor resiko dirugikan secara seksual. Faktor biaya finansial dan faktor investasi emosi cenderung dianggap sebagai pengorbanan yang lebih besar nilainya bagi pria jika dibandingkan dengan wanita. Untuk biaya finansial wanita mempermasalahkan hanya apabila besaran yang mereka keluarkan lebih besar dibanding pasangannya. Jadi bukan kepada jumlahnya, tetapi lebih kepada porsinya. Sedangkan untuk faktor resiko dirugikan secara seksual dianggap sebagai sebuah pengorbanan lebih besar nilainya oleh para wanita jika dibandingkan para pria

Teori Pertukaran Sosial tentang comparison level menyatakan jika yang nilainya lebih baik pasangan yang sekarang maka dia merasa puas dengan hubungannya yang sekarang, dan jika pasangan yang sebelumnya lebih baik nilainya maka mereka merasakan ketidak puasannya dengan hubungan yang sekarang.

Ternyata tidak sesederhana itu, walaupun secara garis besar pernyataan tersebut benar. Informan merasa sulit jika untuk membandingkan nilai antara pasangan yang sekarang dengan pasangan sebelumnya, karena setiap orang punya karakter masing-masing, dan punya kelebihan dan kekurangan masing-masing. Dan ada kecenderungan bahwa pasangan yang sekarang mempunyai nilai lebih karena sekarang informan sedang menjalani hubungan bersamanya, jadi bukan merupakan penilaian yang seimbang. Karena untuk hubungan yang saat ini dijalani ada penilaian khusus mengenai masa depan yang akan mereka jalani bersama dibanding dengan pasangan sebelumnya yang sudah kandas, tidak mempunyai kesempatan lagi di masa depan dibanding dengan pasangan yang sekarang.

Dan juga untuk menyatakan puas atau tidak puasnya ternyata tidak sesederhana apabila nilainya lebih tinggi pasangan yang sekarang akan menjadi lebih puas, karena jika dilihat lebih dalam yang dinilai bukan nilai secara keseluruhan tapi juga nilai secara spesifik semisal pasangan yang dulu mempunyai tubuh yang lebih tinggi dibanding yang sekarang, walaupun 
secara keseluruhan nilainya bagusan yang sekarang tapi tetap ada ketidakpuasan yang dirasakan.

Jadi sangat sulit untuk memberi kepuasan jika pasangan kita mempunyai pasangan yang sangat berkualitas di masa lalu. Hal tersebut dapat menjadi pertimbangan saat akan menjalin hubungan yang baru dengan seseorang.

Teori Pertukaran Sosial tentang comparison level of alternatives, mereka menyatakan jika yang nilainya lebih baik pasangan yang sekarang maka mereka akan tetap pada hubungannya yang sekarang, dan jika alternatif pasangan yang lain lebih baik nilainya maka mereka akan mengakhiri hubungan yang sekarang.

Tetapi sama seperti comparison level, membandingkan nilai seseorang bukanlah hal yang sederhana, walaupun secara naluriah jika ada hal yang lebih baik, kita ingin mendapatkan yang lebih baik.

Banyak faktor yang membuat hal tersebut menjadi tidak sederhana, salah satunya seperti ada sesuatu yang dimiliki oleh seseorang yang tidak bisa digantikan oleh orang lain. Dan ada potensi untuk salah menilai diantara calon alternatif, karena pelaku belum pernah merasakan secara langsung bagaimana jika mempunyai hubungan dengannya. Jika calon alternatif tersebut belum dekat, maka akan dinilai dari faktor pertama yaitu penampilan, dimana dapat mengaburkan penilaian jika secara fisik nilainya bagus tetapi secara kepribadian tidak cocok.

Dan belum tentu alternatif yang lain ini dijamin tertarik dengan pelaku, karena jika dengan pasangan yang sekarang pelaku sudah mendapat kepastian bahwa pasangannya mau dengan dirinya. Maka ketertarikan dari calon alternatif juga mempengaruhi penilaian secara keseluruhan dimana membuat hal tersebut menjadi tidak sederhana.

Proses perpindahan kepada calon alternatif yang memiliki nilai lebih tinggi dari pasangan yang sekarang juga tidak sederhana, memerlukan waktu yang tepat dan memerlukan penyesuaian. Dan seperti kata pepatah "rumput tetangga lebih hijau", bisa jadi calon alternatif lain yang belum dimiliki terlihat nilainya lebih baik, $\mathrm{p}$ [adahal belum tentu ketika menjadi pasangan nilainya ternyata tidak sebaik itu, hanya penasaran saja. Dan rasa ketertarikan terhadap pelaku juga mempengaruhi proses penilaian dan perpindahan terdapat calon alternatif.

Jadi jika pasangan adalah seseorang yang sangat berkualitas yang memiliki banyak calon alternatif pasangan lain yang menginginkannya, sulit untuk tetap membuatnya tinggal pada hubungan yang sekarang. Oleh karena itu cara yang terbaik adalah terus meningkatkan 
kualitas diri alih-alih menghalang-halangi pasangan untuk menjalin hubungan dengan orang lain, karena hal itu tidak mungkin bisa dihalangi.

\section{Saran}

Peneliti berharap pada penelitian selanjutnya dapat dilakukan dengan narasumber yang lebih beragam dan pada topik yang lebih khusus, sehingga semakin memperkaya khazanah pengetahuan dalam hal ini.

Bagi para pengembang aplikasi online dating dan biro jodoh online dapat memberikan edukasi tentang bagaimana meningkatkan keberhasilan melanjutkan hubungan ke tahap yang lebih jauh dalam online dating sehingga semakin memperbanyak penggunanya dan juga para pengguna menjadi lebih terbantu dengan hal tersebut.

\section{Referensi}

\section{$\underline{\text { Buku: }}$}

Aronson, E. 2003. The Social Animal. New York: Freeman.

Baxter, Leslie A.; Braithwaite, Dawn O. 2008. Engaging theories in interpersonal communication: Multiple perspectives. Sage Publications, Inc.

Blau, P. 1964. Exchange and power in social life. New York: Wiley.

Buss, D. M. 2000. The dangerous passion - why jealousy is as necessary as love and sex. New York: Free Press

Buss, D. M. 2007. The evolution of human mating. Acta Psychologica Sinica, 39, 502- 512.

Byrne, D. 1971. The attraction paradigm. New York: Academic Press 
DeLamater, John. 2006. The Handbook of Social Psychology. Kluwer Academic / Plenum Publishers, New York.

Devito, Joseph A. 2002. Human Communication. Pearson

Dunn., R., 2013. Identity Theories and Technology. East Tennessee State University, USA.

Festinger, L. 1954. A theory of social comparison processes. Human Relations, 7, 117-140.

Griffin, Em. 2012. A First Look at Communication Theory. McGraw Hill.

Holme, P., Edling, C. R., \& Liljeros, F. 2004. Structure and time-evolution of an Internet dating community. Social Networks, 26, 155-174

Homans, G. C. 1961. Elementary forms of social behavior. New York: Harcourt.

Katherine, Miller 2005. Communication Theories. New York: McGraw Hill.

Levine, D. 2000. Virtual attraction: What rocks your boat. CyberPsychology \& Behavior, 3, 565-573.

Littlejohn, Stephen W. 2001. Theories of Human Communication. USA: Wadsworth Publishing.

McQuail, Denis. 2005. Mass Communication Theory. $5^{\text {th }}$ ed. London: SAGE Publications.

P.R., Monge; N., Contractor. 2003. Theories of communication networks. Oxford University Press

Pearson, Judy. 2003. Human Communication, McGrawhill company. New York : McGrawHill Company Inc.

Robbins, S. P.; Chatterjee, P.; Canda, E. R. 2012.Contemporary human behavior theory: a critical perspective for social work. Pearson Education, Inc.

Roloff, Michael. 1981. Interpersonal communication: The social exchange approach. Beverly Hills

Ruben, Brent D,Stewart, Lea P, 2005, Communication and Human Behaviour, USA: Allyn and Bacon

Sendjaja,Sasa Djuarsa, 1994, Pengantar Komunikasi, Jakarta: Universitas Terbuka. 
Thibaut, John W. \& Harold H. Kelley. 1959. The Social Psychology of Groups. New York. John Wiley \& Sons, Inc. London. Chapman \& Hall, Ltd.

Thurlow, C., Lengel, L. \& Tomic, A. 2004. Computer mediated communication: Social interaction and the internet. London: Sage

Walster, E., Walster, G. W., \& Berschied, E. 1978. Equity: Theory and research. New York: Allyn \& Bacon.

Walster, E., \& Winch, R. F. 1958. Mate selection: A study of complementary needs. New York: Harper

West, Richard; Turner, Lynn. 2007. Introducing Communication Theory. McGraw Hill.

Zajonc, R. B. 2003. The Selected Works of R.B. Zajonc. New York: Wiley

$\underline{\text { Jurnal: }}$

Ahmed, Ayesha. 2013. E-Arranged Marriages: How have Muslim matrimonial websites affected traditional Islamic courting methods?. Media@LSE, London School of Economics and Political Science ("LSE"), Houghton Street, London WC2A 2AE

Auld, Christopher J.; Case, Alan J. 1997.Social Exchange Processes in Leisure and Nonleisure Settings: A Review and Exploratory Investigation. Journal of Leisure Research 29 (2): 183.

Bapna, Ravi. Ramaprasad, Jui. Umyarov, Akhmed. 2013. One-Way Mirrors and WeakSignaling in Online Dating: A Randomized Field Experiment.Carlson School of Management, University of Minnesota

Bordia, Prashant. Simon Lloyd D. Restubog, Sarbari Bordia, and Robert L. Tang. 2014. Effects of Resource Availability on Social Exchange Relationships: The Case of Employee Psychological Contract Obligations. Journal of Management.

Chaudry, Anjali., Song, Lynda J. 2014. Rethinking Psychological Contracts in the Context of Organizational Change: The Moderating Role of Social Comparison and Social Exchange. The Journal of Applied Behavioral Science 2014, Vol. 50(3) 337-363 
Cooper, A., \& Sportolari, L. 1997. Romance in cyberspace: Understanding online attraction. Journal of Sex Education \& Therapy, 22, 7-14.

Erturk, Alper. 2014. Influences of HR Practices, Social Exchange, and Trust on Turnover Intentions of Public IT Professionals. Public Personnel Management 2014, Vol. 43(1) 140175

Finkel, Eli J., Eastwick, Paul W., Karney, Benjamin R., Reis, Harry T., Sprecher, Susan. 2012. Online Dating: A Critical Analysis From the Perspective of Psychological Science. APS (Association for Psychological Science)

Gibney, Ray., Zagenczyk, Thomas J., Masters, Marick F. 2009. The Negative Aspects of Social Exchange: An Introduction to Perceived Organizational Obstruction. Group \& Organization Management 34(6) 665-697 SAGE Publications

Golden, Timothy D., Veiga, John F. 2015.Self-Estrangement's Toll on Job Performance: The Pivotal Role of Social Exchange Relationships With Coworkers. Journal of Management (sagepub.com)

Helsper, Ellen J., Whitty, Monica T., Lee, Erina. 2009. The Role of the Internet in Reconfiguring Marriages: A Cross-national Study. The Oxford Internet Institute. One St. Giles, Oxford OX1 3JS

Hitsch, Gunter J., Hotacsu, Ali., Ariely, Dan. 2010. What Makes You Click? - Mate Preferences in Online Dating.

Jiang, C., Bazarova, N., \& Hancock, J. 2011. From perception to behavior: Disclosure reciprocity and the intensification of intimacy in computer-mediated communication. Communication Research, 40, 125-143.

Jiang, C., Bazarova, N., \& Hancock, J. 2011. From perception to behavior: Disclosure reciprocity and the intensification of intimacy in computer-mediated communication. Communication Research, 40, 125-143

Lambe, C. Jay; Wittmann, C. Michael; Spekman, Robert E. 2001.Social Exchange Theory and Research on Business-to-Business Relational Exchange. Journal of Business-to-Business Marketing 8 (3): 1-36. 
Lavelle, J. J.; Rupp, D. E.; Brockner, J. 2007.Taking a Multiple Approach to the Study of Justice, Social Exchange, and Citizenship Behavior: The Target Similarity Model. Journal of Management 33 (6)

Lawler, Edward J.; Thye, Shane R. 1999.Bringing Emotions into Social Exchange Theory. Annual Review of Sociology 25: 217-244.

Lowry, Paul Benjamin Lowry; Cao, Jinwei; and Everard, Andrea. 2011. Privacy concerns versus desire for interpersonal awareness in driving the use of self-disclosure technologies: The case of instant messaging in two cultures. Journal of Management Information Systems (JMIS), vol. 27(4), pp. 163-200

Molm, Linda D. 1997. Coercive Power in Social Exchange (Studies in Rationality and Social Change). The Press Syndicate by the University of Cambridge

Morry, M. M. 2007. Relationship satisfaction as a predictor of perceived similarity among cross-sex friends: A test of the attraction-similarity model. Journal of Social and Personal Relationships, 24, 113-138.

Posey, Clay; Lowry, Paul Benjamin; Roberts, Tom L.; and Ellis, Selwyn. 2010. Proposing the online community self-disclosure model: The case of working professionals in France and the UK who use online communities, European Journal of Information Systems (EJIS), vol. 19(2), pp. 181-195

Samp, Jennifer A., and Caren E. Palevitz. 2012. Dating and Romantic Partners. 21st Century Communication: A Reference Handbook. Ed. Thousand Oaks, CA: SAGE, 2009. 323-31. SAGE Reference Online.

Shaker, Fahim. Hafiz, Reaz. Personal Branding in Online Platform.Global Disclosure of Economics and Business, Volume 3, No 3/2014 ISSN 2305-9168(p); 2307-9592(e)

Shtatfeld, Rivka; Barak, Azy. 2009. Factors Related to Initiating Interpersonal Contacts on Internet Dating Sites: A View from the Social Exchange Theory. Interpersona: an International Journal on Personal Relationships 3: 19-37.

Smith, Aaron., Duggan, Maeve. 2013. Online Dating \& Relationships. Pew Research Center's Internet \& American Life Project 
Sprecher, S. 1998. Social exchange theories and sexuality - the use of theory in research and scholarship on sexuality. Journal of Sex Research, 28, 387-408.

Sprecher, S. 2001. Equity and social exchange in dating couples: Associations with satisfaction, commitment, and stability. Journal of Marriage and Family, 63, 599-613

Surma, Jerzy. 2016. Social exchange in online social networks. The reciprocity phenomenon on Facebook.Computer Communications.

Takahashi, Yamagishi, Tanida, Kiyonari, and Kanazawa. 2006. Attractiveness and Cooperation in Social Exchange. human-nature.com/ep

Walster, E., Aronson, V., Abrahams, D., \& Rottman, L. 1966. Importance of physical attractiveness in dating behavior. Journal of Personality \& Social Psychology, 4, 508-516.

Walther, J. B., \& Burgoon, J. K. 1992. Relational communication in computer-mediated interaction. Human Communication Research, 19, 50-88.

Zaman, Muhammad. 2013. Exchange Marriages in a Community of Pakistan: Adequate Social Exchange. The Family Journal: Counseling and Therapy for Couples and Families 2014, Vol 22(1) 69-77 
